Supplement of Hydrol. Earth Syst. Sci., 21, 1827-1847, 2017

http://www.hydrol-earth-syst-sci.net/21/1827/2017/

doi:10.5194/hess-21-1827-2017-supplement

(C) Author(s) 2017. CC Attribution 3.0 License.

(c) (i)

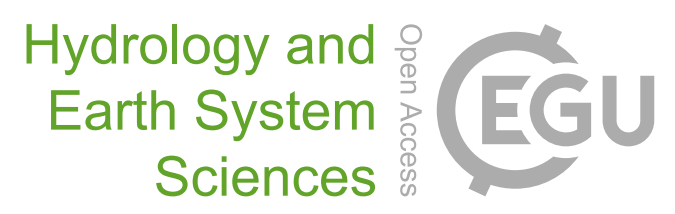

Supplement of

\title{
Evaluating uncertainties in modelling the snow hydrology of the Fraser River Basin, British Columbia, Canada
}

Siraj UI Islam and Stephen J. Déry

Correspondence to: Stephen J. Déry (sdery@unbc.ca)

The copyright of individual parts of the supplement might differ from the CC-BY 3.0 licence. 
Supplementary Table 1: Details of Fraser River main stem at Hope (LF) and major sub-basins within the Fraser River Basin. The list includes information of the sub-basin abbreviations (in parentheses), mean elevation, gauged area, percentage gauged area relative to LF, and latitude and longitude of the gauge at the outlet of each sub-basin (Déry et al. 2012).

\begin{tabular}{|l|c|c|c|c|c|}
\hline \multicolumn{1}{|c|}{ Basin } & $\begin{array}{c}\text { Mean basin } \\
\text { elevation [m] }\end{array}$ & $\begin{array}{c}\text { Gauged area } \\
{\left[\mathbf{k m}^{2}\right]}\end{array}$ & $\begin{array}{c}\text { Gauged area relative } \\
\text { to LF [\%] }\end{array}$ & Latitude $\left({ }^{\circ} \mathbf{N}\right)$ & Longitude $\left({ }^{\circ} \mathbf{W}\right)$ \\
\hline Fraser-Shelley (UF) & 1413 & 32,400 & 14.9 & 54.01 & 122.62 \\
\hline Stuart (SU) & 1097 & 14,200 & 6.5 & 54.08 & 124.27 \\
\hline Nautley (NA) & 1070 & 6030 & 5.3 & 52.84 & 122.59 \\
\hline Quesnel (QU) & 1391 & 11,500 & 3.2 & 52.07 & 123.54 \\
\hline Chilko (CH) & 1756 & 6940 & 25.3 & 50.35 & 121.39 \\
\hline Thompson-Nicola (TN) & 1363 & 54,900 & 100.0 & 49.38 & 121.45 \\
\hline Fraser at Hope (LF) & 1320 & 217,000 & & 5 \\
\hline
\end{tabular}


Supplementary Table 2: The Nash-Sutcliffe coefficient of efficiency (NSE) for the PCIC driven VIC calibration (1979-1990) and validation (1991-2006) periods for six major sub-basins of the FRB.

\begin{tabular}{|c|c|c|}
\hline \multirow{2}{*}{ Basins } & 1979-1990 Calibration & 1991-2006 Validation \\
& & Daily NSE NSE \\
\hline & 0.77 & 0.76 \\
\hline Fraser-Shelley (UF) & 0.70 & 0.86 \\
\hline Stuart (SU) & 0.23 & 0.15 \\
\hline Nautley (NA) & 0.89 & 0.83 \\
\hline Quesnel (QU) & 0.69 & 0.65 \\
\hline Chilko (CH) & 0.86 & 0.80 \\
\hline Thompson- Nicola (TN) & & \\
\hline
\end{tabular}




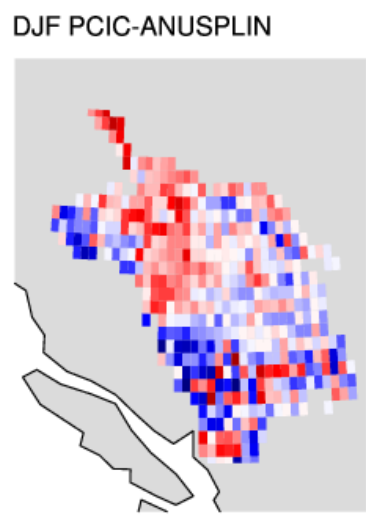

DJF PCIC-NARR

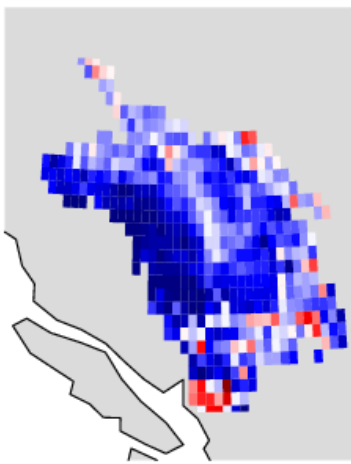

DJF PCIC-UW

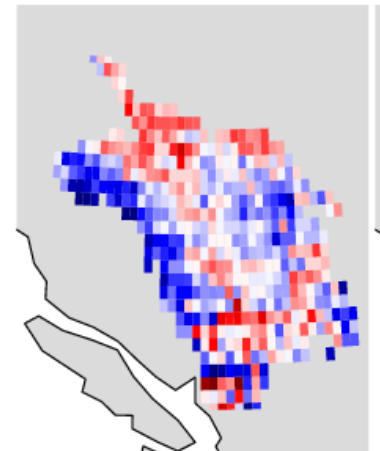

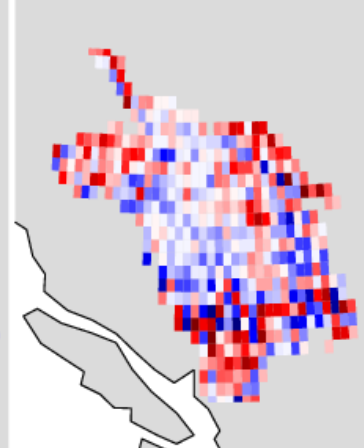

MAM

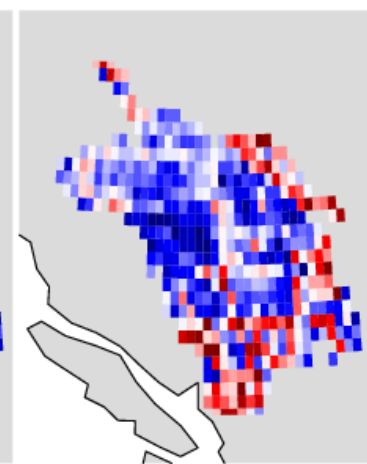

MAM

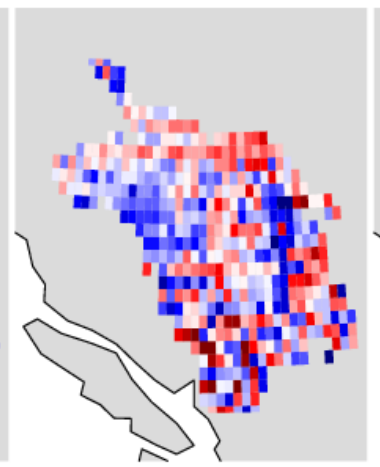

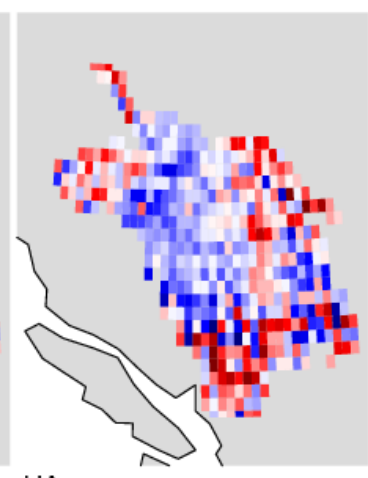

JJA

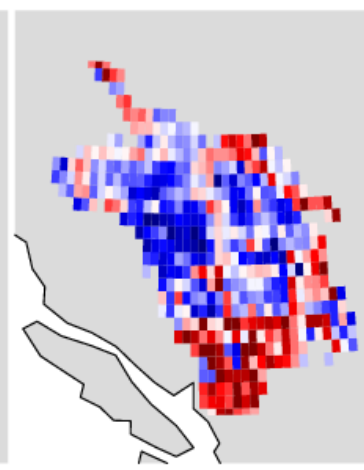

JJA

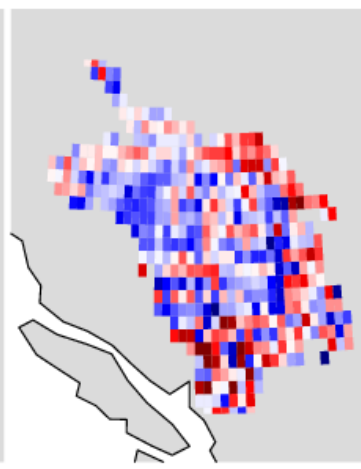

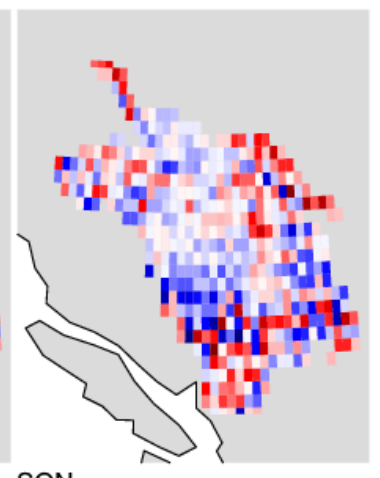

SON

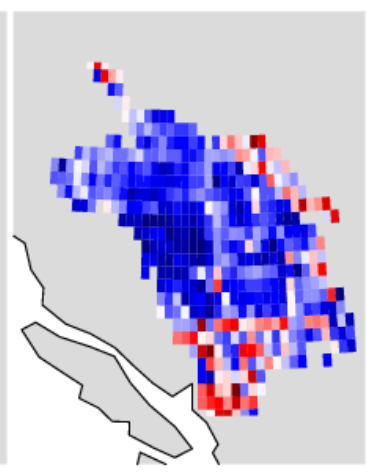

SON

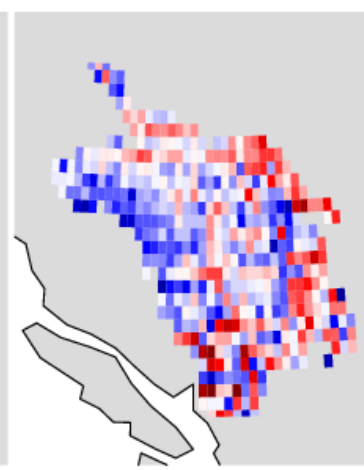

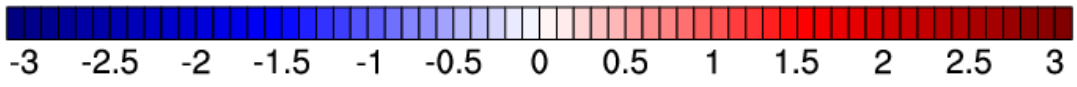

Supplementary Figure 1: Spatial differences of mean seasonal air temperature $\left({ }^{\circ} \mathrm{C}\right)$ based on PCIC-VIC minus ANUSPLIN-VIC (1st row), NARR -VIC (2nd row) and UW (3rd row) simulations, water years 1979-2006. DFJ, MAM, JJA and SON correspond to 5 winter, spring, summer and autumn seasons, respectively. 

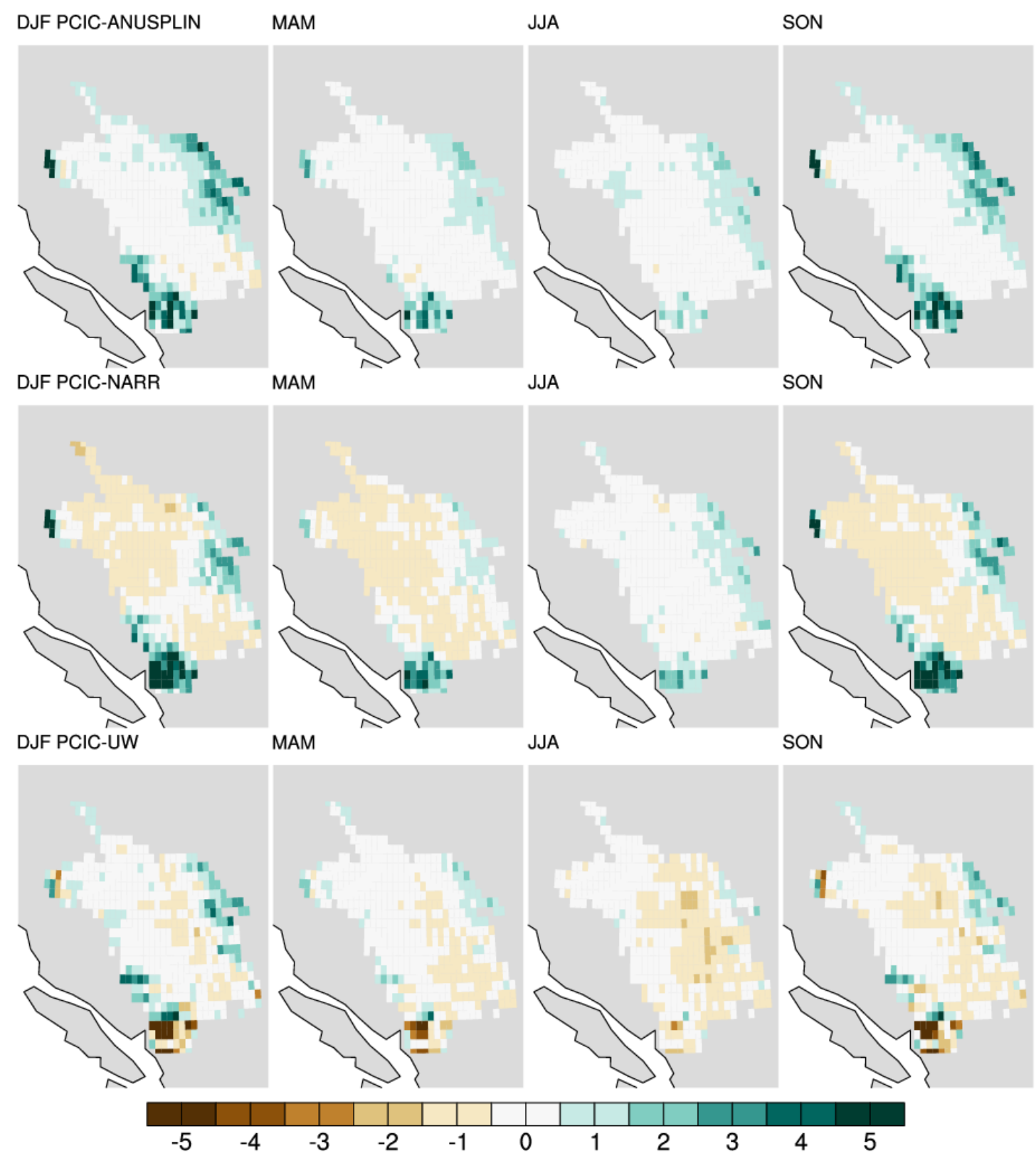

Supplementary Figure 2: Same as Supplementary Figure 1 but for seasonal precipitation $\left(\mathrm{mm} \mathrm{day}^{-1}\right)$. 


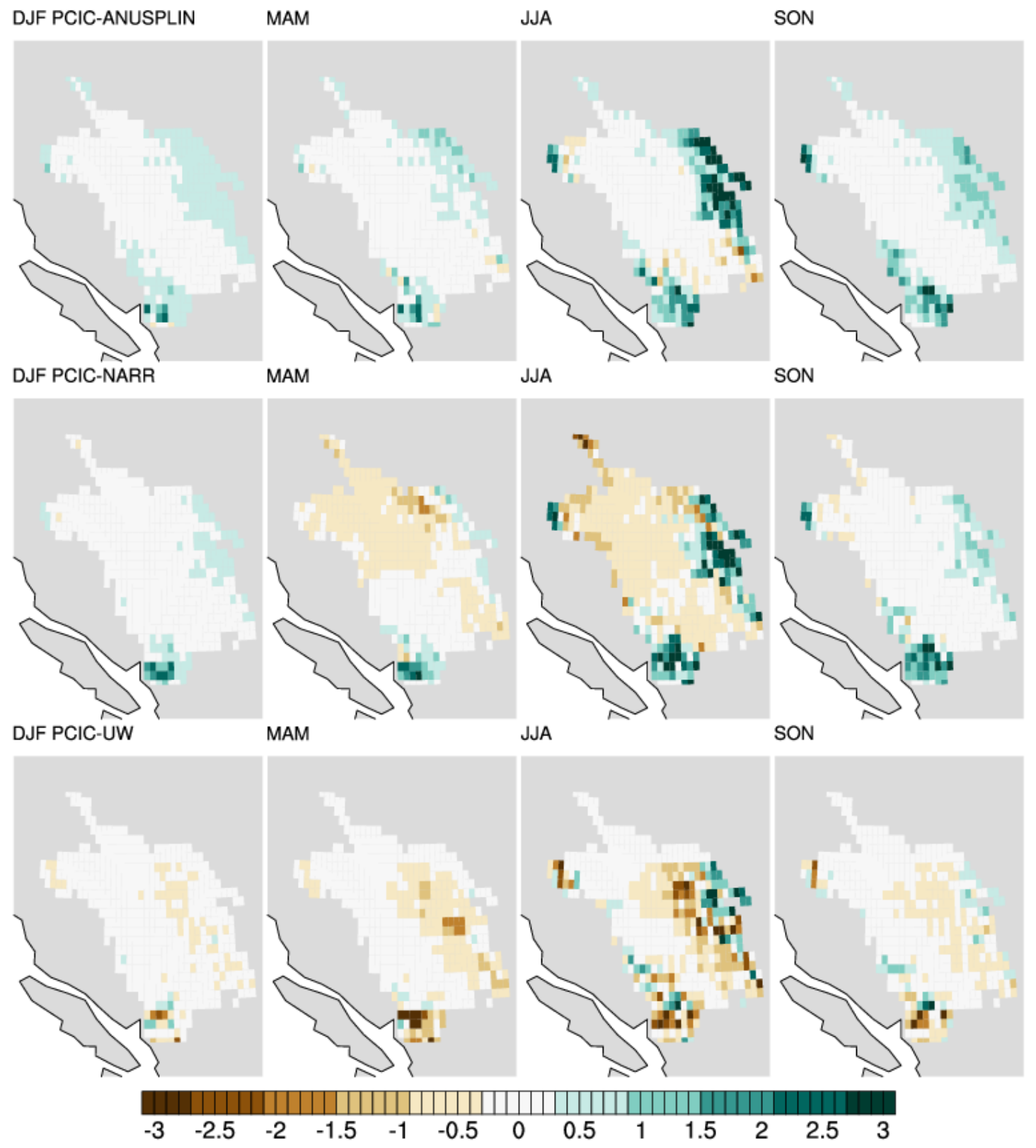

Supplementary Figure 3: Same as Supplementary Figure 1 but for total seasonal runoff (mm day ${ }^{-1}$ ). 

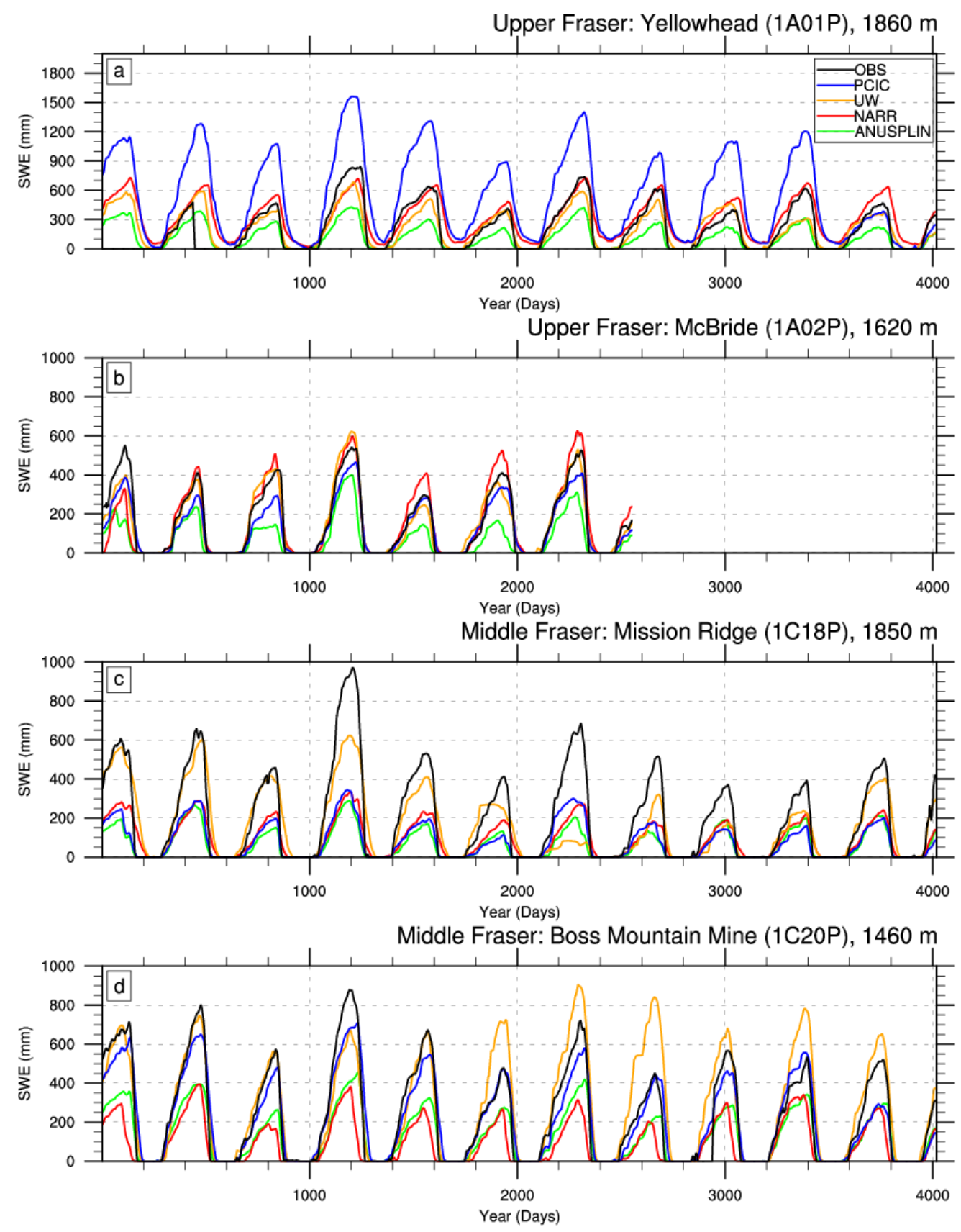

Supplementary Figure 4: Comparison of the ANUSPLIN-VIC, NARR-VIC, UW-VIC and PCIC-VIC simulated daily snow water equivalent (SWE) with the BC snow pillow daily SWE observations in the Upper Fraser at (a) Yellowhead and (b) McBride and in the Middle Fraser at (c) Mission Ridge and (d) Boss Mountain Mine. 

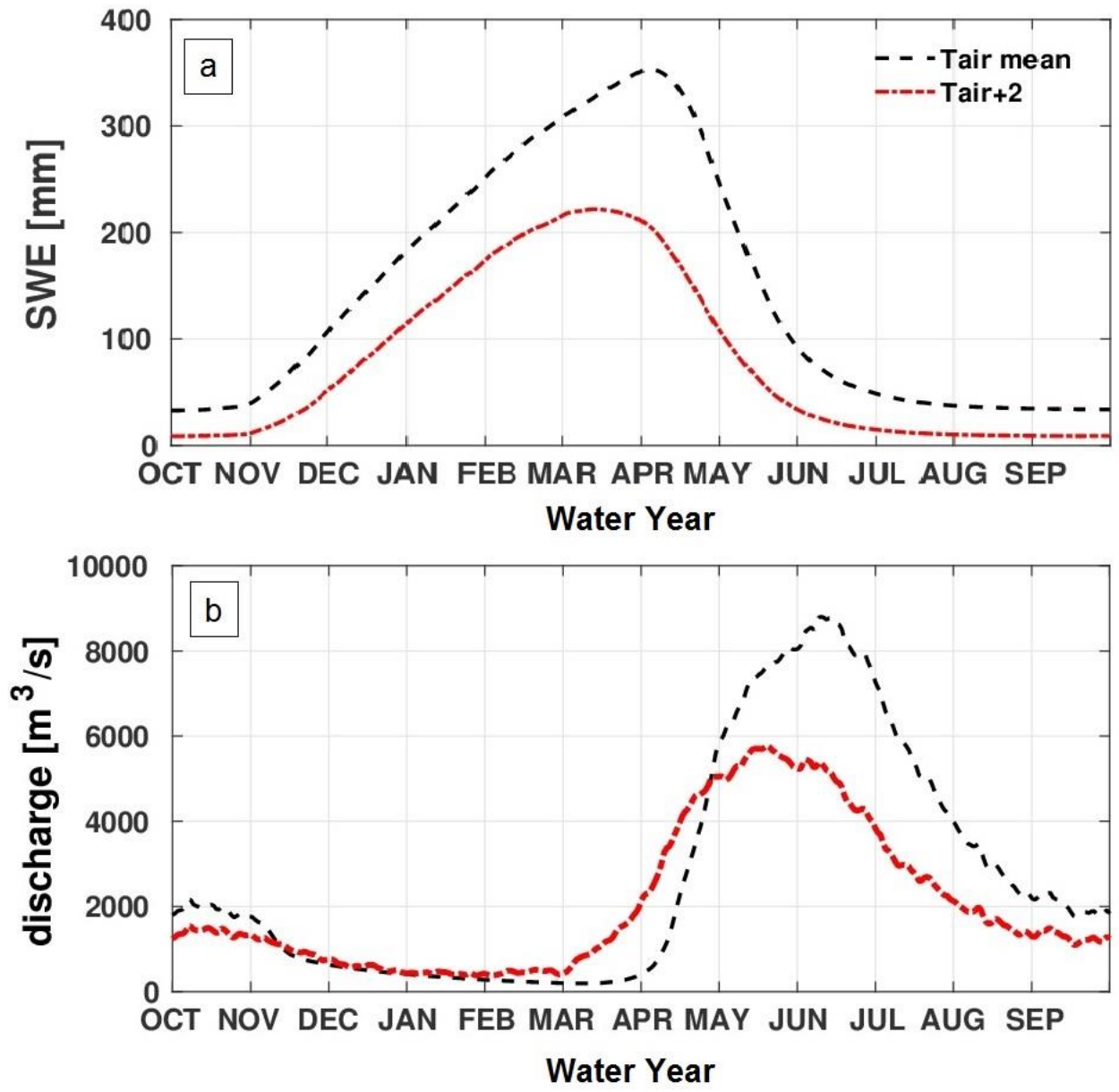

Supplementary Figure 5: Area-averaged time series of daily mean (a) SWE and routed (b) discharge for Fraser River at Hope in the VIC sensitivity simulations (See text for detail). Water year starts on 1 October and ends on 30 September of the following calendar year. 

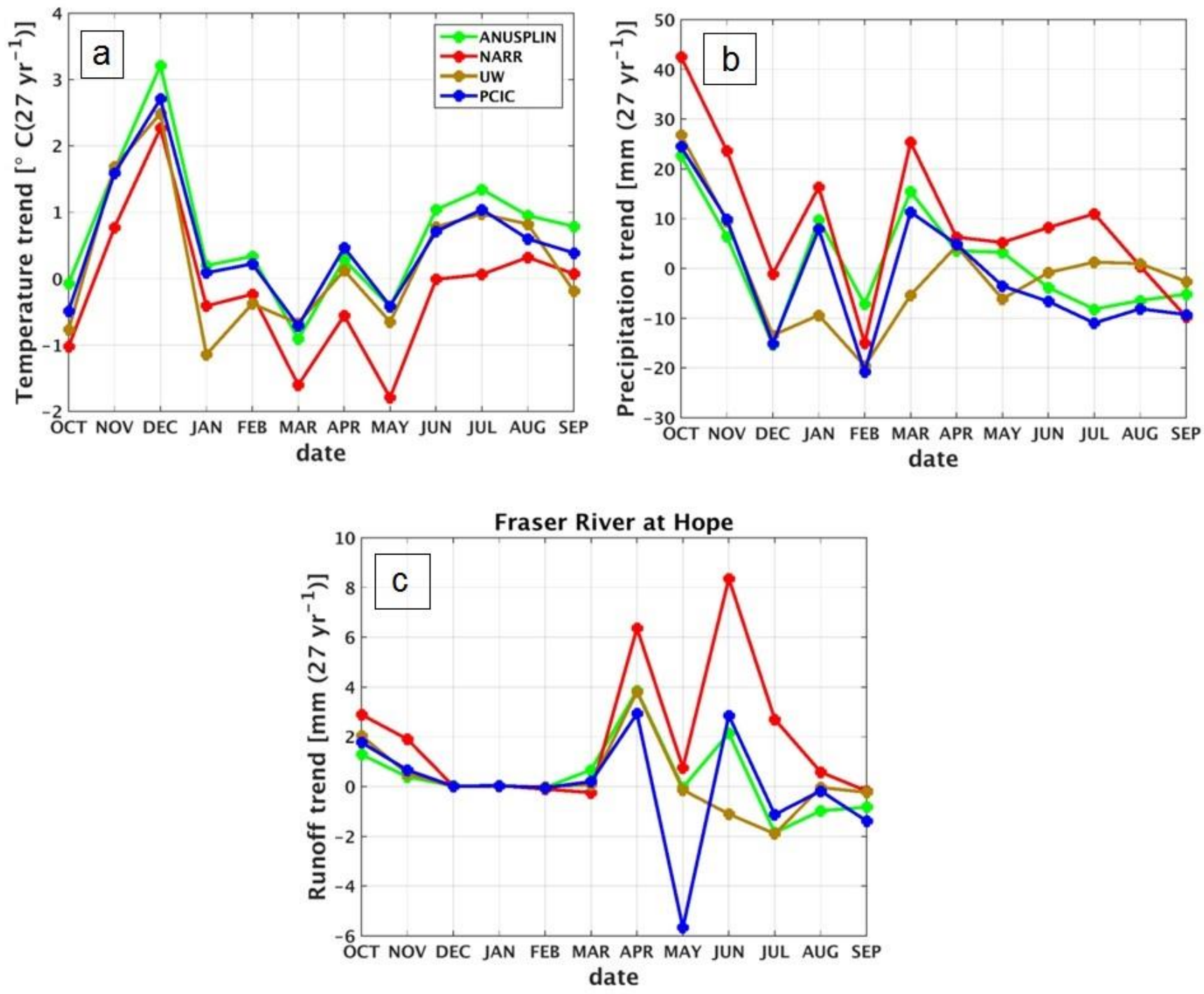

Supplementary Figure 6: Monthly trends in the ANUSPLIN, NARR, UW and PCIC (a) air temperature, (b) precipitation and the VIC simulated (c) runoff. Air temperature and precipitation forcings are averaged across the FRB gridcells whereas runoff is calculated using external routing model for Fraser River at Hope over water years 1979-2006. 


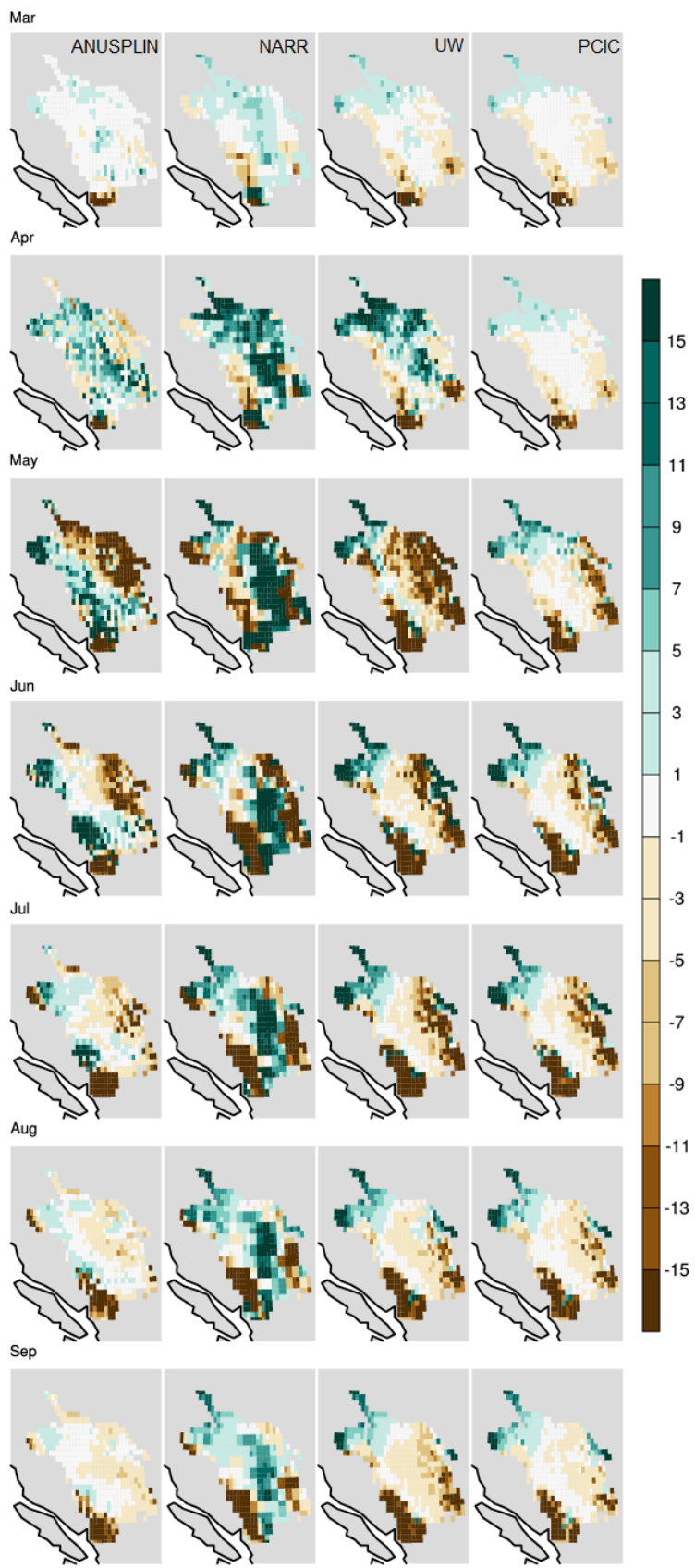

Supplementary Figure 7: Spatial patterns of monthly runoff trends in the ANUSPLIN-VIC, NARR-VIC, UW-VIC and PCIC-VIC simulations over the 1979-2006 time period. March to September months are shown only to cover spring and summer runoff. Column represents VIC simulated runoff driven by different forcing datasets whereas rows are for different months. 

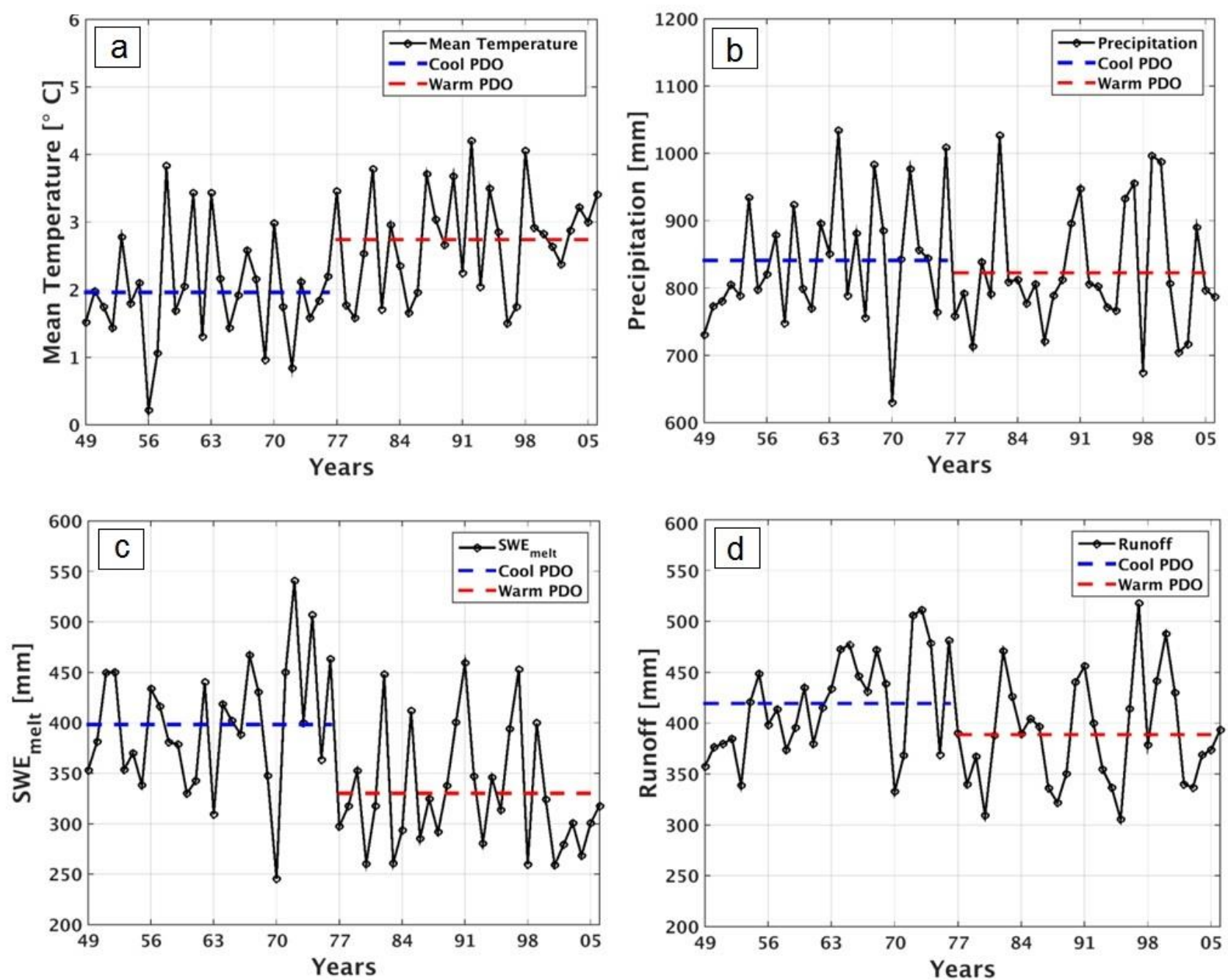

Supplementary Figure 8: Annual variation of mean (a) air temperature, (b) precipitation, (c) $\mathrm{SWE}_{\text {melt }}$ and (d) runoff in cool (blue line) and warm (red line) phases of the PDO. Air temperature and precipitation are extracted from the UW forcing dataset

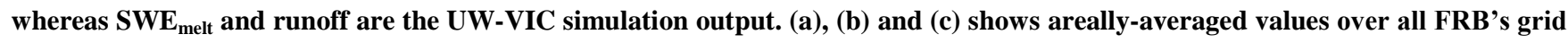
cells whereas runoff is calculated using external routing model for Fraser River at Hope. 